\title{
Assessment of Iron Oxide Nanoparticle Ecotoxicity on Regeneration and Homeostasis in the Replacement Model System Schmidtea mediterranea
}

\author{
Thao A. Tran 1,\#, Michelle Hesler1,\#, Oscar H. Moriones2, Alba Jimeno-Romero 1,3, Benjamin Fischer1, \\ Neus G. Bastús'2, Victor Puntes 2,4,5, Sylvia Wagner1, Yvonne L. Kohl1 and Luca Gentile1,6,7,8 \\ ${ }^{1}$ Fraunhofer Institute for Biomedical Engineering IBMT, Sulzbach, Germany; ${ }^{2}$ Institut Català de Nanociència i Nanotecnologia (ICN2), CSIC, Barcelona \\ Institute of Science and Technology (BIST), Barcelona, Spain; ${ }^{3}$ Research Centre for Experimental Marine Biology and Biotechnology, University of \\ the Basque Country, Plentzia, Spain; ${ }^{4}$ Institució Catalana de Recerca i Estudis Avançats (ICREA), Barcelona, Spain; ${ }^{5}$ Vall d'Hebron Institut de Recerca \\ (VHIR), Barcelona, Spain; ${ }^{6}$ Current addresses: Hasselt University, Campus Diepenbeck, Diepenbeck, Belgium; ${ }^{7}$ University of Applied Sciences \\ Kaiserslautern, Campus Zweibrücken, Zweibrücken, Germany; ${ }^{8}$ INSERM - University of Strasbourg, Strasbourg, France
}

\begin{abstract}
Iron oxide nanoparticles (IONs) are used in a number of applications from food to cosmetics and from medical applications to magnetic storage. In spite of the 550 tons produced each year in Europe alone, no effective dose limit recommendations are established and the overall risks connected to IONs are still debated. The incorporation of IONs in daily life raises a concern about their effects on the environment, on living organisms, and on human health. In this study, we used freshwater planarians to assess the nanoecotoxicity of IONs. Planarians are free-living invertebrates known for their astonishing regenerative ability. Because of their sensitivity to toxicants, they are often used to determine the effects of toxic, genotoxic, and carcinogenic environmental compounds with an approach in line with the 3Rs (Reduce, Refine, Replace) principle. Planarians were exposed to $1 O N s$ at concentrations up to $1 \mathrm{mg} / \mathrm{ml}$ and their effects were evaluated at the behavioral, morphofunctional, and molecular levels, with a special emphasis on the regeneration process. Our results indicate that IONs did not affect the stem cell population dynamics, nor did they induce substantial changes in either homeostatic or regenerating planarians. As positive controls, gold nanoparticles coated with the pro-apoptotic anti-cancer drug hexadecylmethylammonium bromide and highly concentrated polystyrene nanoparticles were used; these all elicited toxic effects. Therefore, we conclude that IONs at environmental concentrations are safe for planarians, and that the planarian is a powerful model system that can replace vertebrate animal models in nanoecotoxicology research and for nanoecotoxicology studies.
\end{abstract}

\section{Introduction}

Iron oxide nanoparticles (IONs) are used in numerous applications such as medical contrast agents, cosmetics, food additives, varnishes, coatings, pigmented thermoplastics, biosensors, and for cryobiotechnological applications (Gupta and Gupta, 2005; Kornberg et al., 2017; Lee et al., 2008; Minard and Wind, 2002; Peng et al., 2008; Semelka and Helmberger, 2001). These nanoparticles are also used as delivery vectors for targeted can- cer therapies (Shen et al., 2012; Thomas et al., 2010; Veiseh et al., 2010; Weinstein et al., 2009). In Europe only, 550 tons IONs are produced annually, which are released into the environment as a consequence of both the synthesis and processing of raw materials and the use, the recycling, or the disposal of nanoparticle-containing products. The uptake of IONs might happen at different stages of the life cycle (Bundschuh et al., 2018; Gottschalk et al., 2009; Piccinno et al., 2012; Tolaymat et al., 2017). In this way, not only workers but the whole environment is exposed to IONs

\footnotetext{
\# contributed equally
}

Received February 6, 2019: Accepted April 16, 2019; Epub April 26, 2019; ( The Authors, 2019

ALTEX 36(4), 583-596. doi:10.14573/altex.1902061

Correspondence: Luca Gentile, PhD, Hasselt University, Campus Diepenbeck, Agoralan Building D, 3590 Diepenbeck, Belgium; University of Applied Sciences Kaiserslautern, Campus Zweibrücken, Amerikastr. 1, 66482 Zweibrücken, Germany (luca.gentile@uhasselt.be)

Yvonne L. Kohl, PhD, Fraunhofer Institute for Biomedical Engineering,

Joseph-von-Fraunhofer-Weg 1, 66280 Sulzbach, Germany

(yvonne.kohl@ibmt.fraunhofer.de)
This is an Open Access article distributed under the terms of the Creative Commons Attribution 4.0 International license (http://creativecommons.org/licenses/by/4.0/) which permits unrestricted use, distribution and reproduction in any medium, provided the original work is appropriately cited. 
(Wang et al., 2016). Research in the field of nanoecotoxicology has provided high-quality information about behavior, fate, and ecotoxicity of nanomaterials, but some knowledge gaps remain, mainly owing to the high variability of the end product and the environmental conditions that could modify the uptake (Lead et al., 2018). The biological impact of engineered nanomaterials (NMs) in general and IONs among them largely depends on their physicochemical features (e.g., size, surface charge, solvents used) and the transformations they undergo (e.g., aggregation, corrosion, dissolution). Moreover, depending on the type of interactions that NMs have with the environment, (e.g., the proteins to which they are associated that form the so-called corona, which can be "soft" or "hard") (Casals et al., 2010, 2011), they may acquire a different biological identity, and thus have different effects on living organisms (Casals et al., 2012; Casals and Puntes, 2012; Ding et al., 2013; Lynch et al., 2007; Podila et al., 2012).

Relevant in vivo studies suggested that pulmonary exposure to IONs may induce inflammation (Park et al., 2010, 2015; Sadeghi et al., 2015; Srinivas et al., 2012; Szalay et al., 2012), pulmonary fibrosis (Zhu et al., 2008), genotoxicity (Ishino et al., 2015; Totsuka et al., 2014), and extra-pulmonary effects (Zhu et al., 2009). Chamorro and colleagues reported accumulation of IONs in the liver, spleen, and duodenum of growing chickens when administered orally in the low-dose range (chronic exposure) (Chamorro et al., 2015). Cohort studies on workers exposed to IONs during the production of iron oxide pigments showed an increase in oxidative stress biomarkers in exhaled breath condensate (Pelclova et al., 2016). Andujar and colleagues identified welding-related nanoparticles in lung tissue sections from welders (Andujar et al., 2014).

In contrast to in vitro studies that reported no cytotoxic effects from ION exposure up to $100 \mu \mathrm{g} / \mathrm{ml}$ (Coricovac et al., 2017; Freyria et al., 2012), others reported macrophage dysfunction in a concentration range of 6.25 to $12.5 \mu \mathrm{g} / \mathrm{ml}$ (Kodali et al., 2013), DNA damage induced by $10 \mu \mathrm{M}$ IONs (Sighinolfi et al., 2016), and mitochondrial oxidative stress for doses between $10-50 \mu \mathrm{g} / \mathrm{ml}$ (Dwivedi et al., 2014). An $\mathrm{IC}_{50}$ range of $6.4-23 \mu \mathrm{g} / \mathrm{ml}$ was determined for several human cell lines after 72 hours exposure to IONs (Namvar et al., 2014). Oxidative stress is likely the consequence of the release of free iron ions after cell internalization (Andujar et al., 2016; Wang et al., 2016; Xing et al., 2015).

Ferric iron is a common water pollutant near coal and hard rock mines (Cadmus et al., 2018). Therefore, the ecotoxicity of IONs has been studied in several aquatic organisms along the food chain. Adverse effects have been detected in all aquatic models (algae, daphnia, mussel, carp) (Baumann et al., 2014; García et al., 2011; Lei et al., 2016; Magro et al., 2018; Remya et al., 2015; Taze et al., 2016). Most of these studies reported an increase in the production of reactive oxidative species (ROS) and DNA damage. However, there is still a lack of information about the effects of IONs on the stem cells.
Freshwater planarians (Phylum platyhelminthes) are free-living invertebrates found in both salty and freshwater ecosystems (Reddien and Sánchez Alvarado, 2004). They are known for their regeneration ability that hinges on the presence of pluripotent stem cells in the adult animal (Wagner et al., 2011). Also for this reason, planarians are routinely used as a model to assess toxicity, lethality, teratogenesis, and neurotoxicity of chemicals (Best and Morita, 1991; Lowe et al., 2015; Zhang et al., 2013), to study developmental toxicity (Hagstrom et al., 2015), and to investigate the effects of environmental pollutants and nanopollutants on the stem cell compartment in vivo (Mouton et al., 2011; Kustov et al., 2014; Salvetti et al., 2015; Van Roten et al., 2018). Planarians have a relatively simple body plan, without a body cavity but with organs and tissues of high complexity, including a highly cephalized central nervous system, a gastrovascular cavity that both absorbs and distributes the nutrients, protonephridia, and both female and male reproductive organs. Planarians can regenerate any body part, including the whole head, and certain planarians have lost the ability to reproduce sexually (e.g., the asexual strain of Schmidtea mediterranea) and reproduce only by binary fission; the missing body structures regenerate in approximately one week. Remarkably, development and regeneration in $S$. mediterranea occur through very similar processes (Reddien and Sánchez Alvarado, 2004).

The exceptionally short time scale by which regeneration progresses, the inexpensive husbandry, and the sensitivity to environmental pollutants make planarians an alternative model to vertebrates for studying the effects of pollutants in vivo (Stevens et al., 2017; Van Roten et al., 2018). In comparison to other alternative models, like zebra fish larvae and nematodes, planarians are capable to react sensitively to several chemicals (Hagstrom et al., 2015), providing the additional opportunity to study nanotoxicity in adult individuals that possess a highly dynamic stem cell population. Planarian regeneration depends on the presence of a large population of adult pluripotent stem cells, historically called neoblasts. With few exceptions (pharynx pocket, region in front of the photoreceptors), these cells are spread throughout the entire body and can differentiate into any of the cell types that constitute the animal (Cebrià et al., 2007; Reddien and Sánchez Alvarado, 2004; Rink, 2013; Scimone et al., 2014; Tran and Gentile, 2018; Wagner et al., 2011). The neoblasts are the only dividing cells in planarians. After injury, they migrate, proliferate, and differentiate into the missing structures, under the control of complex gradients of morphogens secreted in turn by the cells at the wound and by the cells of the muscle layers (Owlarn et al., 2017; Scimone et al., 2014; Vogg et al., 2014; Witchley et al., 2013; Wurtzel et al., 2017).

In this study, we investigated the effects of IONs on both regeneration and homeostasis in the planarian $S$. mediterranea. The use of the planarian model system allowed us to study the effects of nanopollutants in a highly dynamic stem cell system and to push

\section{Abbreviations}

DCFDA, 2',7'-dichlorofluorescin diacetate; DPI, days post-injection; ICP-MS, induced coupled plasma-mass spectroscopy; IONs, iron oxide nanoparticles; NPs, nanoparticles; PAM, planarian artificial media; PSNP, polystyrene-nanoparticle; ROS, reactive oxygen species; RT-QPCR, real-time quantitative polymerase chain reaction; TEM, transmission electron microscopy; TMAOH, tetramethylammonium hydroxide; XRD, X-ray diffraction 
forward the adoption of research strategies in line with the 3R (Reduce, Refine, Replace) principle (Russell and Burch, 1959), where the substitution of vertebrate models with invertebrate or in vitro models is encouraged. In order to gain a comprehensive picture of the ways IONs could affect aquatic life, we incubated planarians with IONs under waterborne conditions or injected IONs directly into the gastrovascular system. Our results indicate that IONs up to $1 \mathrm{mg} / \mathrm{ml}$ neither affect planarian homeostasis nor regenerative capability, suggesting that IONs have no adverse effect on planarians, even at high concentrations similar to those found in polluted mining sites (Appiah-Adjei et al., 2019).

\section{Animals, materials, and methods}

\subsection{Animals}

The sexual strain of planarian Schmidtea mediterranea was used in this study. Planarians were maintained at $18-20^{\circ} \mathrm{C}$ in planarian artificial media (PAM, Cebrià and Newmark, 2005) with a $12 \mathrm{~h}$ light/dark cycle, as previously described (Cebrià and Newmark, 2005). Animals were fed with veal liver twice a week and starved for one week before ION treatment in order to minimize the effects of feeding on the stem cells. Animals used for the experiments had a size of 2-4 $\mathrm{mm}$.

Planarians are excluded from the current legislation regulating scientific research on animals. The animal husbandry was nonetheless in accordance with current best practice; all individuals involved with the care and the use of the animals were trained properly. Planarians used in this study were treated with respect and handled only when necessary, in order to keep the stress low. No unnecessary harm was inflicted that was not required to conduct the experiments. The minimal number of animals able to give statistically relevant data was calculated based on previous experience.

\subsection{Chemicals}

Iron (II) chloride $\left(\mathrm{FeCl}_{2} .4 \mathrm{H}_{2} \mathrm{O}, 98 \%\right)$, iron (III) chloride $\left(\mathrm{FeCl}_{3}\right.$, $\geq 98 \%$ ), tetramethylammonium hydroxide (TMAOH, $1.0 \mathrm{M}$ in $\mathrm{H}_{2} \mathrm{O}$ ), sodium hydroxide $(\mathrm{NaOH}, \geq 98 \%)$, DMEM, high glucose, GlutaMAX ${ }^{\mathrm{TM}}$ supplement, pyruvate, penicillin-streptomycin $(10,000 \mathrm{U} / \mathrm{ml})$, and foetal bovine serum, qualified, E.U.-approved, South America origin were all purchased from SigmaAldrich (Munich, Germany) and used before their expiration date.

Polystyrene nanoparticles (PSNPs) of an approximate size of $80 \mathrm{~nm}$ (PlasmaChem GmbH, Berlin, Germany) and hexadecyltrimethylammonium bromide-coated gold NPs (CTAB-AuNPs), with an average size of $8.43 \pm 0.85 \mathrm{~nm}$ and a $\zeta$-potential of +31.2 $\pm 2.86 \mathrm{mV}$ were used for the experiments at concentrations of 0.1 , 1 , and $10 \mathrm{mg} / \mathrm{ml}$ (PSNPs) and $0.01 \mathrm{mg} / \mathrm{ml}$ (AuNPs).

\subsection{Synthesis of iron oxide nanoparticles}

TMAOH-stabilized, $7 \mathrm{~nm}$ mean diameter IONs were synthesized based on Massart's method (Massart, 1981), with modifications. IONs were synthesized in the aqueous phase, using milli-Q grade water. 5 or $10 \mathrm{mmol} \mathrm{FeCl}_{3}$ were dissolved in $50 \mathrm{ml}$ deoxygenated water and added dropwise to $50 \mathrm{ml}$ deoxygenated $1 \mathrm{M}$ TMAOH. After $30 \mathrm{~min}$ of vigorous stirring under nitrogen stream, the
$\mathrm{Fe}_{3} \mathrm{O}_{4}$ precipitate was washed by soft magnetic decantation and redissolved in $100 \mathrm{ml}$ of $10 \mathrm{mM}$ TMAOH to obtain the final stable colloidal solution of IONs.

\subsection{Physicochemical characterization of iron oxide nanoparticles}

In order to study the stability of IONs in PAM, IONs were incubated in PAM for $1 \mathrm{~h}$ and then sonicated for $10 \mathrm{~s}$. Afterwards, stock and PAM solutions of IONs were characterized using different techniques: UV-visible spectrophotometry (UV/Vis), dynamic light scattering, laser-Doppler-microelectrophoresis, transmission electron microscopy (TEM), X-ray diffraction (XRD), and induced coupled plasma-mass spectroscopy (ICP-MS).

\section{$U V$-Vis spectroscopy}

UV-visible spectra were acquired with a Shimadzu UV-2401 PC spectrophotometer. $\mathrm{A} \mathrm{Fe}_{3} \mathrm{O}_{4} \mathrm{NP}$ solution was placed in a cell in a $5 \%$ dilution $(\mathrm{v} / \mathrm{v})$, and spectral analysis was performed in the 300-800 $\mathrm{nm}$ range at room temperature.

\section{Dynamic light scattering}

A Malvern ZetaSizer Nano ZS instrument (Malvern Instruments, UK) operating at a light source wavelength of $532 \mathrm{~nm}$ and a fixed scattering angle of $173^{\circ}$ was used to measure ION size. One milliliter of $5 \%(\mathrm{v} / \mathrm{v})$ IONs was placed in a cell.

\section{$\zeta$-potential measurement}

A Malvern ZetaSizer Nano ZS instrument (Malvern Instruments, UK) was used for $\zeta$-potential measurement. The samples were prepared by diluting the native ION suspension 1:10 in ultrapure water or PAM. For $\zeta$-potential measurements, the diluted samples were analyzed in a Zeta cell DTS 1060C. All measurements were carried out at $25^{\circ} \mathrm{C}$. The $\zeta$-potential reported herein was obtained as the average of three independent measurements (100 repetitions per measurement) performed on each sample.

\section{Transmission electron microscopy (TEM)}

Images were acquired with a FEI Tecnai G2 F20 S-TWIN HR(S) TEM equipped with an energy-dispersive X-ray spectroscopy (EDX) detector, operated at an accelerated voltage of $200 \mathrm{kV}$. A droplet of the sample was drop cast onto a piece of ultrathin carbon-coated 200-mesh copper grid (Ted-pella, Inc.) and left to dry. More than 200 particles were computer-analyzed and measured to calculate size distributions.

\section{$X$-ray diffraction $(X R D)$}

Data were collected on a PANalytical X'Pert diffractometer using a $\mathrm{CuK} \alpha$ radiation source $(\lambda=1.541 \AA)$. In a typical experiment, the $2 \theta$ diffraction (Bragg) angles were measured by scanning the goniometer from $25^{\circ}$ to $90^{\circ}$. The samples were prepared by centrifugation of the slurry containing the NPs at 40,000 x g, to precipitate the NPs. The supernatant was discarded and samples were dried at room temperature to avoid further NP transformations. Peak positions and their full width at half maximum (FWHM) were determined using the X'Pert HighScore program after baseline correction. 
Induced coupled plasma-mass spectroscopy (ICP-MS)

The samples for ICP-MS measurement were prepared as follows: first, the colloidal solution containing the NPs was centrifuged at $40,000 \mathrm{x}$ g for $45 \mathrm{~min}$. The supernatant and the pellet were analyzed separately. Each part was heated in concentrated aqua regia for complete dissolution of the metals and further diluted to an optimal concentration for ICP-MS. The treated pellet and the supernatant were analyzed on the NexION 300 ICP MS (Perkin Elmer). The concentration of Fe in the supernatant was $0.464 \mathrm{mg} / \mathrm{ml}$, while in the pellet it was $11.2 \mathrm{mg} / \mathrm{ml}$. This indicated a $96 \%$ rate conversion of the Fe used into NPs.

\subsection{ION exposure and injection}

Two particle exposure pathways were investigated during this study: waterborne and diet-borne. For waterborne exposures, planarians were exposed to $\mathrm{Fe}_{3} \mathrm{O}_{4}$ in PAM at different concentrations $(0.1 \mathrm{mg} / \mathrm{ml}$ and $1 \mathrm{mg} / \mathrm{ml})$ for 14 days in 6-well plates, 2 animals in each well.

For the diet-borne exposure, IONs were injected directly into the gastrovascular cavity of planarians using a Nanoject II (Drummond, Pennsylvania, USA) and borosilicate glass capillaries with filaments (BF120-94-10, Science Product, Hofheim, Germany) under the microscope (Nikon SMZ745T, Düsseldorf, Germany). Working solutions were freshly prepared at the moment of injection by sonicating the stock solution for $10 \mathrm{~s}$, and diluting it with PAM to achieve the desired nominal concentrations of $0.1 \mathrm{mg} / \mathrm{ml}$ and $1 \mathrm{mg} / \mathrm{ml}$. Three injections of $92 \mathrm{nl}$ each on three consecutive days were administered.

\subsection{Morphological analysis and assessment of the regeneration ability}

Homeostatic animals were assessed with regard to the animals' survival rate, the viability of the different cell populations, the production of ROS, and the gene expression of ION-treated intact animals after 14 days exposure. Animal behavior was assessed as the ability to quickly escape light when exposed to the light source of the microscope (negative phototaxis response).

The regeneration capability was assessed in animals amputated at the pharyngeal level 1 day after the last injection of IONs. The two fragments produced were morphologically examined under the stereo microscope (Nikon SMZ25, Düsseldorf, Germany) at different time points post-amputation over 15 days.

Assessments were done by placing both homeostatic and regenerating animals on a petri dish on ice $(100 \mathrm{~mm} \times 15 \mathrm{~mm})$ under the stereo microscope to capture their morphology and their regenerating ability. Data were generated in a minimum of three independent experiments, using three animals per experiment.

\subsection{Real-time quantitative polymerase chain reaction (RT-qPCR)}

Control and ION-treated planarians (2 animals per sample) were processed for RNA extraction using a NucleoSpin RNA kit (Macherey-Nagel, Düren, Germany). Total RNA quantified with a Nanodrop 2000 (Thermo Fisher, Dreieich, Germany) was re- verse-transcribed to cDNA using the High Capacity Reverse Transcription Kit (ThermoFisher, Dreieich, Germany). Real-time PCR analysis was performed on a QuantStudio 6 Flex Real-Time PCR System (ThermoFischer, Dreieich, Germany) using the $2 \mathrm{x}$ Taqman Master Mix (ThermoFisher, Dreieich, Germany) and a 20x primer and probe mix (IDT, Leuven, Belgium). The following genes were quantified: pcna, smedwil, p53, agat1, NB321g, $H B 1911 g, m y h c$, and gapdh as reference gene. Each sample was run in technical triplicates. Relative gene expression was calculated with the double delta cycle threshold $(\Delta \Delta \mathrm{CT})$ method, as previously reported (Boiani et al., 2005; Livak and Schmittgen, 2001) The sequences of the oligonucleotides used in this study are provided in Table $\mathrm{S} 1^{1}$.

\subsection{Cell viability, reactive oxygen species (ROS), and cell population analysis}

Planarians were dissociated into single cells and these were stained for flow cytometry as previously described (Moritz et al., 2012).

Cell viability was assessed by Calcein-AM / propidium iodide double staining $(0.05 \mu \mathrm{g} / \mathrm{ml} / 1 \mu \mathrm{g} / \mathrm{ml}$, respectively; Sigma-Aldrich, Munich, Germany).

The production of ROS was assessed using the DCFDA Cellular ROS detection kit (Promega, Mannheim, Germany). Cells were incubated with $20 \mu \mathrm{M}$ DCFDA for $30 \mathrm{~min}$ at RT. Cells were then assessed by flow cytometry at 485/535 nm (FL2, $488 \mathrm{~nm}$ ). ROS production was determined by the change in percentage of fluorescent signals compared to control samples. $1 \mathrm{mM} \mathrm{H}_{2} \mathrm{O}_{2}$ was used as positive control.

The planarian cell sub-populations were analyzed as previously described (Scimone et al., 2014). Briefly, cells were incubated with $10 \mu \mathrm{M}$ Hoechst 33342 (ThermoFisher, Dreieich, Germany). Sub-population data were acquired on a FACS Aria III (BD, Heidelberg, Germany) by plotting the blue emission of the dye (FL1, $405 \mathrm{~nm}$ ) in function of the red emission indicating cell size (FL6, $800 \mathrm{~nm}$ ). In this way, stem cells (X1) in the S/G2/M phases of the cell cycle have the highest signal in the blue channel, compared to either stem cells in $\mathrm{G} 0$ and progenitor cells (X2) or differentiated cells (Xin). Xin cells, with a relatively large cytosol, have the highest signal in the red channel. Data are shown as the average of three independent experiments, where cells from four animals were pooled for each sample.

\subsection{Statistical analysis}

R studio and GraphPad Prism 5.0 were used for the statistical analysis. Percentage of live cells, different cell populations, and ROS production levels obtained by flow cytometry analysis are expressed as mean $\pm \mathrm{SD}$. Relative gene expression is expressed as mean \pm SEM. Student's t-test was used to analyze flow cytometry data. ANOVA was used to compare the variance of qPCR data, followed by Tukey's post-hoc test. The Prcomp function of $\mathrm{R}$ was used for the principle component analysis of gene expression data.

1 doi:10.14573/altex.1902061s 


\section{Results and discussion}

\subsection{Physicochemical characterization of the magnetic IONs}

The mean size of the IONs, as determined via TEM, was $11 \pm 1.8 \mathrm{~nm}$ (Fig. 1A). The calculated concentration by ICP-MS was $5 \times 10^{15}$ $\mathrm{NP} / \mathrm{ml}\left(0.05 \mathrm{mmol} \mathrm{Fe}_{\mathrm{x}} \mathrm{O}_{\mathrm{y}} / \mathrm{ml} ; 11.7 \mathrm{mg} \mathrm{Fe} \mathrm{O}_{\mathrm{y}} / \mathrm{ml}\right)$. UV-Vis spectra of the IONs verified the characteristics of the iron oxide (Fig. 1B). The XRD spectra of the IONs showed that the prepared magnetic nanoparticles were $\mathrm{Fe}_{3} \mathrm{O}_{4}$ of high purity (Fig. 1C). Sharp diffraction peaks were seen in the X-ray diffraction patterns of the prepared magnetic IONs, indicating good crystallization. The positions and intensities of the diffraction peaks were identified and described by the JCPDS Card No. (79-0417) of crystalline magnetite. No extraneous peaks were observed, demonstrating that the prepared magnetic IONs were of high purity (Fig. 1C). The peaks indexed as planes (220), (311), (400), (422), (511), and (440) corresponded to a cubic unit cell, characteristic of a cubic spinel structure, confirming the crystalline structure of the magnetite nanoparticles. The size distribution profile by intensity of the synthesized IONs was measured via dynamic light scattering. The obtained mean value of intensity after three measurements was $126.7 \pm 71.7 \mathrm{~nm}(\mathrm{PdI} 0.268 \pm 0.006)$ (Fig. 1D). The $\zeta$-potential was $-37.5 \pm 2.15 \mathrm{mV}$.

We took into consideration that NPs released into the environment undergo sequential processes that may change their chem- ical reactivity, surface charge, aggregation, or disaggregation, which ultimately determines their potential toxic effects. A significant number of biological systems are complex aqueous media composed of electrolytes, proteins, and metabolites, which can interact with the inorganic surface of the NPs, promoting different physicochemical transformations that modify their biological effects and may ultimately lead to unexpected (including adverse and toxic) effects (Piella et al., 2017; Reidy et al., 2013). The extent of the reactions of NPs is determined by their intrinsic properties (material, size, shape, concentration, crystallinity, surface charge, and coating) and the medium in which they are dispersed (ionic strength, pH) (Piella et al., 2017). Many NPs are unstable and tend to form aggregates after exposure to cell culture media, which modifies the effects they have on biological systems as it influences their reactivity and bioavailability. Owing to the higher percentage of surface atoms and the colloidal form, NPs acquire a more stable thermodynamic state at a faster time scale than their bulk counterparts (Bastús et al., 2012; Casa1s et al., 2012); in turn, this translates into higher rates of aggregation, oxidation, dissolution, and interaction with proteins (Liu and Hurt, 2010; Mudunkotuwa and Grassian, 2011; Piella et al., 2017; Reidy et al., 2013; Wang et al., 2014). Therefore, the size distribution profile of the IONs was also determined after incubation in PAM, the medium in which planarians are kept. The mean value of intensity in PAM was $5022 \pm 761.6 \mathrm{~nm}$ (PdI 0.264 \pm 0.045 ) (Fig. 1D) and the $\zeta$-potential was also negative in PAM

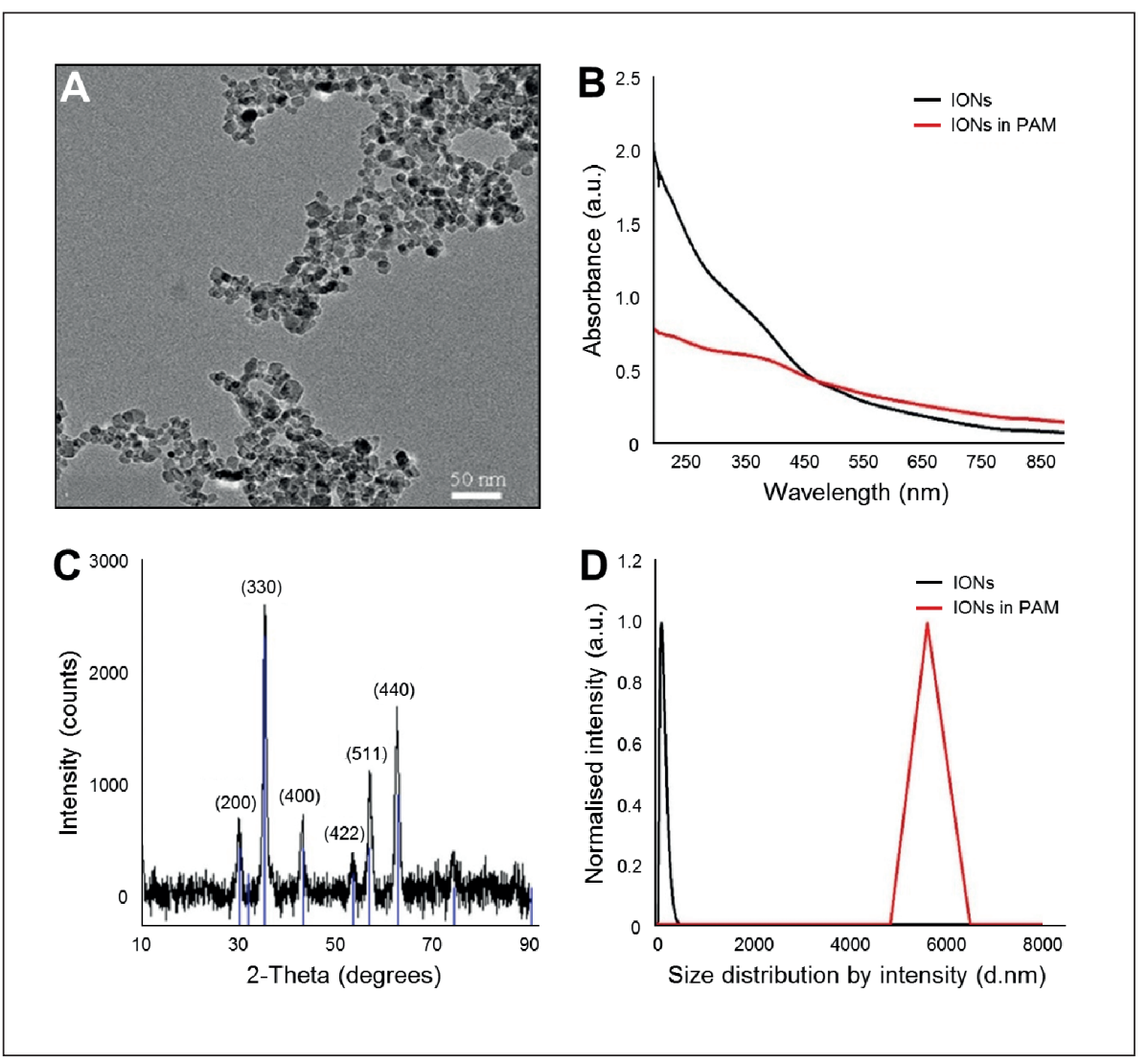

Fig. 1: Physicochemical characterization of the $\mathrm{Fe}_{3} \mathrm{O}_{4}$ nanoparticles (IONs)

(A) Representative TEM of the IONs used in the study. (B) UV-Vis spectrum of IONs before and after dilution in planarian artificial medium (PAM). The spectrum was taken using $5 \%(\mathrm{v} / \mathrm{v})$ IONs in Milli-Q water, after $10 \mathrm{~s}$ sonication. (C) XRD spectrum of the $7.0 \mathrm{~nm}$ IONs taken in a diffractometer using $\mathrm{CuK}_{\mathrm{a}}(\lambda=1.54 \AA)$ as a radiation source. Reference as magnetite taken from Harcourt et al. (1942). The standard pattern for JCPDS Card No. (79-0417) magnetite - synthetic is shown as a blue line. No extraneous peaks were observed, demonstrating that these were high purity $\mathrm{Fe}_{3} \mathrm{O}_{4}$ magnetic nanoparticles. (D) Size distribution profile of the synthesized IONs, before and after dilution in PAM. The size distribution profile obtained by intensity showed a heavy aggregation of IONs into clumps owing to the ionic strength of the medium. 
$(-23.7 \pm 0.36 \mathrm{mV})$. This was confirmed by the UV-Vis spectrum, which presented a decreased intensity owing to particle aggregation (Fig. 1B). The significant increase in mean size confirmed the heavy aggregation caused by the ionic strength of PAM.

\subsection{Effects of IONs on planarian homeostasis}

Effects induced by IONs on planarian homeostasis were evaluated 14 days after their first exposure to IONs. This part of the study included analysis of the survival rate, the behavioral changes, the ROS production, the viability and relative composition of the different cell populations, and gene expression. Animals treated with IONs were compared to positive and negative control groups.

\subsubsection{Survival rate and behavioral changes}

In order to test ION toxicity in a waterborne exposure scenario, animals were exposed to PAM spiked with different ION concentrations $(0.1 \mathrm{mg} / \mathrm{ml}, 1 \mathrm{mg} / \mathrm{ml})$. After 14 days of continuous exposure, no significant differences were found between the treated and the control groups concerning the overall morphology and the survival rate (data not shown). In contrast, all planarians $(n=9)$ exposed to $0.01 \mathrm{mg} / \mathrm{ml}$ gold NPs coated with the pro-apoptotic anti-cancer drug hexadecylmethylammonium bromide died within 30 minutes (Fig. S1 ${ }^{1}$ ). Also, planarians exposed to IONs did not display any behavioral biases modifying their ability to move normally and to escape from a light source (negative phototaxis response; data not shown).

To simulate the effect of diet-borne IONs taken up through the food chain, NPs were injected directly into the gastrovascular cavity of living planarians three times. Successful injection is illustrated with trypan blue in Figure S2 ${ }^{1}$. Fourteen days postinjection (dpi) planarians administered with either $0.1 \mathrm{mg} / \mathrm{ml}$ or $1 \mathrm{mg} / \mathrm{ml}$ IONs showed no behavioral changes. The survival rate was $100 \%(n=12)$ in all groups (data not shown). This is in contrast to what we observed after injection of highly concentrated $(10 \mathrm{mg} / \mathrm{ml})$ PSNPs. All the injected animals elicited some morphological defects, like the loss of the photoreceptors (Fig. S4A ${ }^{1}$ ) or the partial regression (i.e., tissue lysis) of either the head or the tail portion (Fig. S4B-E ${ }^{1}$ ).

However, IONs injected into the gastrovascular system distributed into different organs. In order to assess whether ION accumulation could affect homeostasis at both cellular and molecular levels, we further investigated the effects of diet-borne IONs with regard to the production of reactive oxygen species, the ratio of the cell sub-populations, and gene expression.

\subsubsection{Production of reactive oxygen species (ROS)}

The generation of ROS is a known consequence of exposure to iron (Baker et al., 1997; Li et al., 2009) and has been described as a major effector of the toxicity of metal NPs, as it triggers inflammation, genotoxicity, fibrosis, and cancer (Dayem et al., 2017; Shvedova et al., 2012). Oxidative stress is also a crucial contributor to the toxicity of environmental toxicants (Leung et al., 2008). Since we found no effects of IONs on cell viability, regardless of the concentration used (Fig. 2A), we further investigated ROS production in planarians injected with the highest

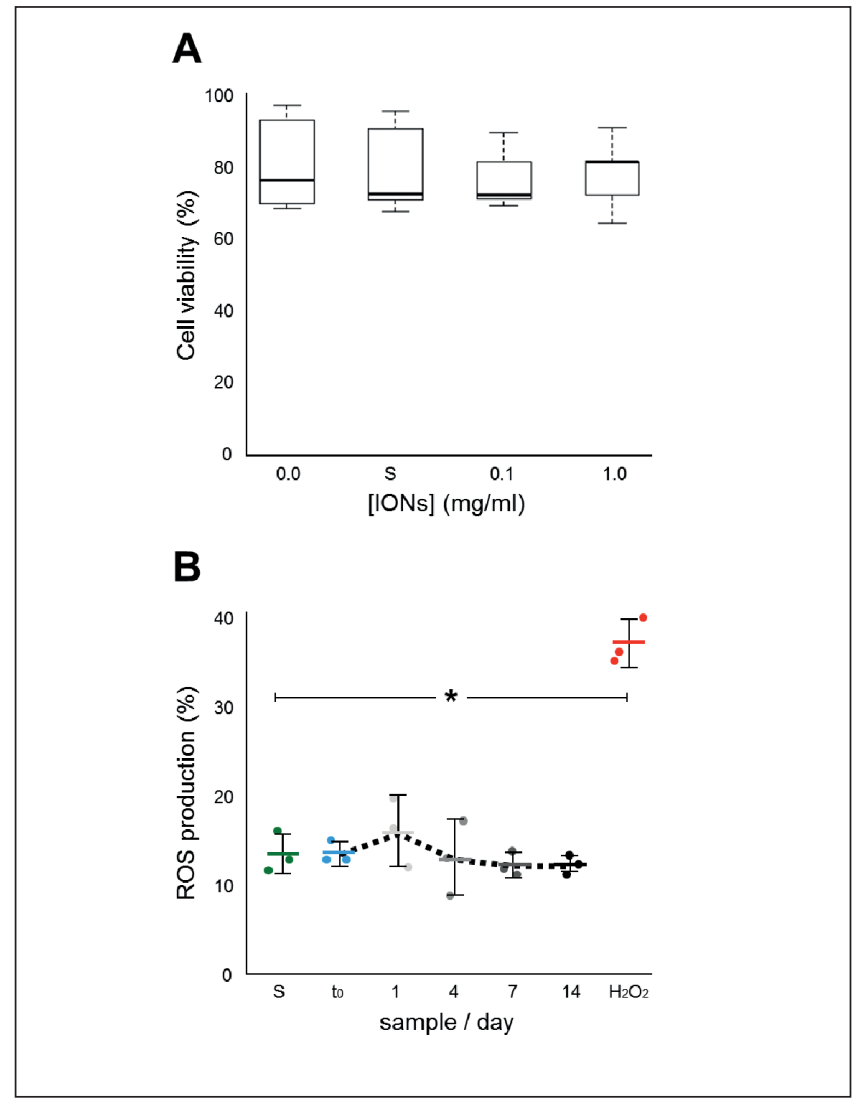

Fig. 2: Effects of IONs on cell viability and ROS production in homeostatic planarians

(A) The boxplot displays the cell viability in animals exposed to $0.0,0.1,1.0 \mathrm{mg} / \mathrm{ml} \mathrm{IONs}$ or the solvent alone (S), as measured by flow cytometry. Live/dead ratio was assessed 14 days postexposure by staining the cells with Calcein-AM $(\mathrm{Ca})$ and propidium iodide (PI). Cells were considered viable if they were $\mathrm{Ca}^{+} / \mathrm{PI}^{-}$.

(B) The dotplot shows the ROS production measured in animals exposed to $1 \mathrm{mg} / \mathrm{ml}$ IONs after different time points (0-14 days post-exposure), compared with both negative ( $\mathrm{S}=$ solvent alone) and positive $\left(\mathrm{H}_{2} \mathrm{O}_{2}\right)$ controls. ROS production was assessed by measuring the fluorescence intensity of Carboxy-H2DCFDA, following manufacturer's instructions. The mean and the $S D$ of $n=$ 3 biological replicates is shown, as well as the trend line over the course of the experiment (dashed line). ${ }^{*} p \leq 0.05$

concentration $(1 \mathrm{mg} / \mathrm{ml})$ of IONs. As shown in Figure 2B, ROS production in ION-treated animals was comparable with the negative control groups ( $\mathrm{t}_{0}$ and solvent alone), while animals treated with hydrogen peroxide $\left(\mathrm{H}_{2} \mathrm{O}_{2}\right)$ showed a significant increase $(37 \pm 2.6 \%, \mathrm{p}=0.018)$ in the ROS level.

\subsubsection{Planarian cell sub-populations}

To further investigate possible ION-induced effects at the cellular level, we focused on the planarian adult stem cell population, which is responsible for maintaining homeostasis by guaranteeing cellular turnover (Gentile et al., 2011; Rink, 2013). We there- 
A

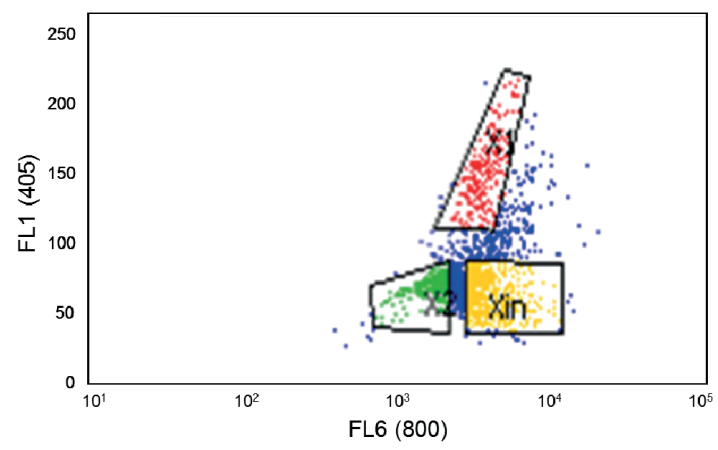

B
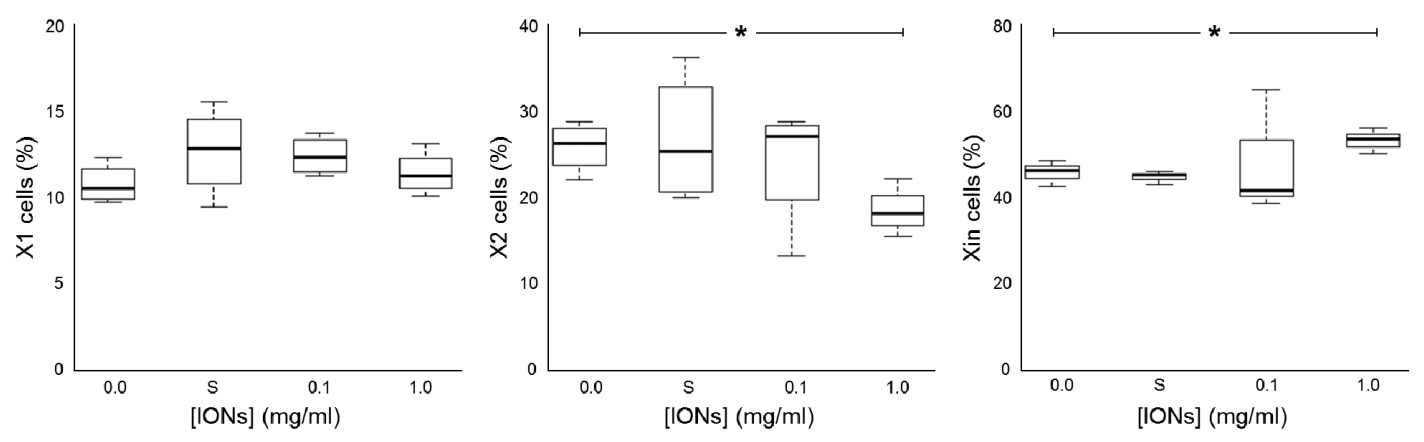

Fig. 3: Effects of the gastrovascular exposure to IONs on the planarian cell sub-populations

(A) Hoechst blue / Hoechst red plot displaying the three cell sub-populations (stem cells, progenitor cells, and differentiated cells; X1, X2, Xin, respectively) defined by DNA content (blue channel) and size (red channel) in wild-type animals. (B) The boxplots show the proportion of X1, X2, and Xin sub-populations in animals injected with $0.0,0.1,1.0 \mathrm{mg} / \mathrm{ml} \mathrm{IONs}$ or the solvent alone (S). Measurements were performed at $14 \mathrm{dpi}, \mathrm{n}=3$ biological replicates. * $\mathrm{p} \leq 0.05$

fore examined whether the presence of IONs affected the balance between stem cells, progeny cells, and differentiated cells. Planarians at 14 dpi were dissociated into single cells, which were subjected to flow cytometry analysis. Following the proposed gating strategy (Fig. 3A), three distinctive planarian cell populations were detected, X1, X2, and Xin. Actively dividing stem cells in the $\mathrm{S} / \mathrm{G} 2 / \mathrm{M}$ phases are found in the $\mathrm{X} 1$ gate; small stem cells in the G1 phase are found in the X2 gate together with small progenitor cells, while large, non-dividing cells are found in the Xin gate, which is by definition extremely heterogeneous (Hayashi et al., 2006; Reddien et al., 2005). Data showed no significant difference in the X1 population upon treatment with IONs: In the control and the solvent groups, X1 represented $10.7 \pm 2.5 \%$ and $12.3 \pm 5.3 \%$ of the total cells, respectively, where in ION-treated animals they

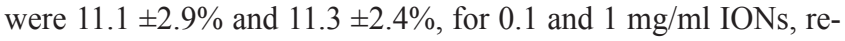
spectively (Fig. 3B, left). Animals treated with $1 \mathrm{mg} / \mathrm{ml} \mathrm{IONs}$ showed a slight decrease in X2 cells (Fig. 3B, center) compared to control, and a corresponding increase in Xin cells (Fig. 3B, right; $\mathrm{p} \leq 0.05$ in both cases). The interaction of the IONs with the gut lining could result in physical damage of the tissue, followed by the induction of inflammation. In turn, this could increase both the differentiation rate of the stem cells and the commitment of the progenitor cells, resulting in the reduction of the X2 gate in favor of the Xin gate.

\subsubsection{Gene expression}

Some NPs have been reported to have no effect on the survival of animal models but did have effects at the gene expression level (Bahadar et al., 2016). In order to fully understand the activity of IONs on homeostatic planarians, we performed real time qPCR analysis to investigate whether exposure to IONs could alter expression of the genes involved in the dynamics of the stem cell population. In planarian, adult stem cells are very sensitive to stress (e.g., irradiation) and respond by activating or shutting down genes that regulate the stem cell population (Hayashi et al., 2006; Eisenhoffer et al., 2008; Van Roten et al., 2018). Therefore, changes in the expression of stem and/or progeny cell markers could indicate the effects of a downstream cascade of cellular/molecular mechanisms in response to the stimulus exerted by IONs.

We selected well-known stem and progenitor cell markers to examine the molecular effects of IONs on the stem cell balance, using ubiquitously expressed gapdh as a reference gene. Inter- 


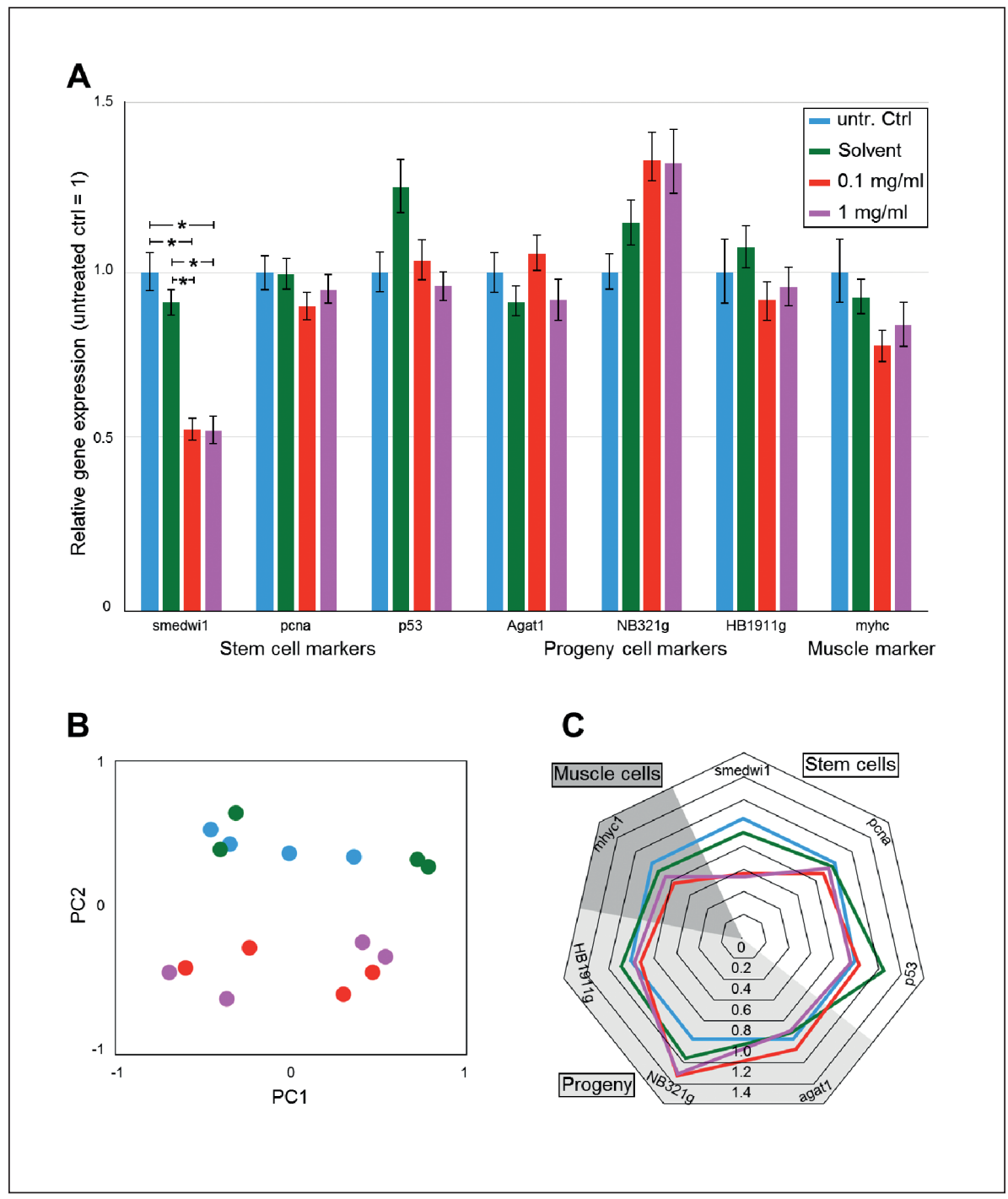

Fig. 4: Effects of gastrovascular exposure to IONs on gene expression

(A) Expression of genes relative to the housekeeping gene gapdh (reference) and the untreated control (calibrator $=1$ ), as measured by qPCR. The analysis was carried out in animals at $14 \mathrm{dpi}, \mathrm{n}=3$ biological replicates and $n=2$ technical replicates.

$(B, C)$ Principal component analysis and radar chart showing how the analyzed samples clustered (B) and how the balance between the stem and the progeny cells' genes was influenced by the injection of IONs into the gastrovascular system (C). * $p \leq 0.05$

estingly, the expression of the pan stem cell marker smedwil (Reddien et al., 2005) roughly halved in ION-treated animals at both concentrations used (Fig. 4A; $\mathrm{p} \leq 0.05$ ). The other stem cell markers considered, pcna and p53 (Orii et al., 2005; Pearson and Sánchez Alvarado, 2010), on the other hand, did not change upon ION treatment. Also the early (NB321g, HB1911g) and the late post-mitotic progeny markers (Eisenhoffer et al., 2008) did not show any significant change, although a slight increase in the expression of $N B 321 \mathrm{~g}$ was consistently observed in ION-treated animals at both 0.1 and $1 \mathrm{mg} / \mathrm{ml}$ concentration (Fig. 4A). As a negative control, the expression of the muscle cell marker myhc (Hayashi et al., 2010) was also assessed, which showed no expression changes (Fig. 4A).

The gene expression data were also analyzed via principal component analysis (PCA) in order to spot an overall effect of the exposure to IONs (Fig. 4B). ION-treated animals clustered separately from untreated ones, suggesting that, altogether, the expression of stem and progenitor cell markers was affected by the exposure to IONs. The slight change of balance in the expression of stem and progeny cell markers can be also appreciated in the radar chart, where the reduction of smedwil was counterbalanced by the increase of NB321g (Fig. 4C).

Altogether, the gene expression data aligned to the flow cytometry data in supporting the hypothesis that more stem cells undergo differentiation upon exposure to IONs, as both the X2 gate and the expression of the pan stem cell marker smedwil decreased (Fig. 3B, center; Fig. 4). This could indicate a physiological response of the animals aimed to preserve homeostasis in the presence of the IONs. Such a change, however, did not influence the mitotic activity of the stem cell population at both the cellular (Fig. 3B, left) and molecular (Fig. 4) levels.

Overall, the data collected on the survival rate, the behavioral changes, the ROS production, the balance among the cell sub-populations, and the gene expression strongly suggested that IONs up to $1 \mathrm{mg} / \mathrm{ml}$ do not have any significant negative effect on planarian homeostasis after 14 days of exposure. The mild ef- 


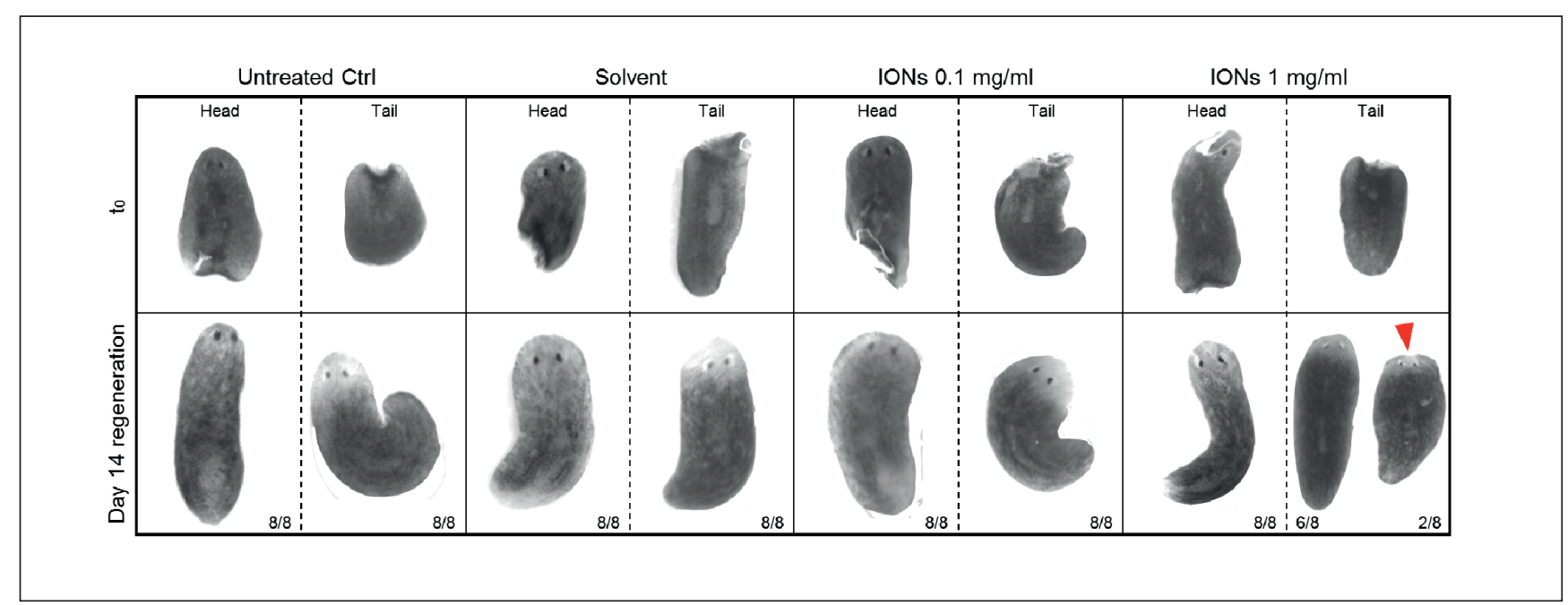

Fig. 5: Effects of the gastrovascular exposure to IONs on the regeneration capabilities of planarians

The panel shows the morphology of freshly amputated head and tail fragments (top panel) and their regeneration at $14 \mathrm{dpi}$ (lower panel). The specimen shown are representative of all the fragments used $(n=16$ fragments for each of the 4 conditions considered, 8 head and 8 tail fragments).

fects observed at the levels of the cell populations and of the gene expression induced by the exposure to IONs were possibly the physiological response to the physical presence of particles, ultimately aiming to preserve and maintain homeostasis.

\subsection{Effects of IONs on planarian regeneration}

One of the most significant endpoints to test the toxicity of a pollutant in planarians is their ability to regenerate after amputation. Thanks to the broad distribution of the adult pluripotent stem cells throughout the mesenchymal space, planarians can regenerate their whole body from a tiny fragment (Morgan, 1989; Wagner et al., 2011). Regeneration is a complex, stepwise process in which the stem cells proliferate and differentiate into the different cell types. When a body part is lost due to amputation or damage, planarians form a non-pigmented tissue called blastema, in which stem cells undergo massive proliferation, are patterned according to the position within the body, and finally differentiate into the missing tissues and organs. Eventually, re-establishment of the correct body proportions and re-wiring of the new tissues with the old ones take place body-wide (Gentile et al., 2011; Rink, 2013).

We assessed whether exposure to IONs during regeneration exerts negative effects not observed in homeostatic animals. We injected IONs at concentrations of either 0.1 or $1 \mathrm{mg} / \mathrm{ml}$ and amputated the animals one day after the last injection, at the pharyngeal level. The two fragments produced (hereafter referred to as head and tail fragments) were monitored daily over 15 days to assess changes in the regeneration process.

All fragments ( $n=16 /$ group) from the 4 groups considered (untreated control, solvent alone control, $0.1 \mathrm{mg} / \mathrm{ml} \mathrm{IONs} \mathrm{and}$ $1 \mathrm{mg} / \mathrm{ml}$ IONs) were able to fully regenerate. No morphological abnormalities or delays in the regeneration speed were observed (Fig. 5), suggesting that exposure to IONs at the concentrations tested does not influence the regeneration ability of planarians.
A similar scenario was observed in regenerating planarians injected with either 0.1 or $1 \mathrm{mg} / \mathrm{ml}$ polystyrene NPs (PSNPs; Fig. $\mathrm{S} 3^{1}$ ). A slight change in the shape of the anterior edge observed in 2 tail fragments at 15 dpi (arrowhead in Fig. 5) owed probably to the small fragment size. The affected animals recovered normal shape after a few additional days.

\subsection{Effects of ION agglormerates}

NPs in the environment tend to form aggregates of micron size (Watanabe et al., 2013), and particle agglomerates were shown to have biological effects different from those of individual particles (Kornberg et al., 2017). Moreover, agglomeration can potentially lead to an inaccurate evaluation of the toxic effect of nano- $-\mathrm{Fe}_{3} \mathrm{O}_{4}$ in the environment, since the IONs quickly clump together in solvent media (Sharma et al., 2014) and smaller particles are suggested to display higher toxicity owing to their ability to penetrate cells more efficiently (Duffin et al., 2008; Kobayashi et al., 2009; Shang et al., 2014).

To assess the effects of "weathered" IONs, we induced agglomeration of IONs and administered them to planarians. We compared ION agglomerates in PAM (i.e., without sonication) with the free ION-suspensions tested so far (Fig. 2-5). Non-sonicated IONs, simulating environmental weathered IONs, aggregated once added to PAM (mean size $10149 \pm 1018 \mathrm{~nm}$, $\zeta$-potential -5.58 $\pm 0.52 \mathrm{mV}$ ). The agglomeration of nanoparticles is predicted to reduce their penetration through the cell membrane (Oberdörster et al., 2005). On the other hand, larger structures are more likely recognized by the animal's immune system, which may cause inflammation (Gualtieri et al., 2012).

We injected non-sonicated IONs into the gastrovascular system of planarians, with a similar procedure as the sonicated ones, and observed their behavior. No differences were found in the animal survival rate and in cell viability (Fig. S5 ${ }^{1}$ ). Similar to sonicated IONs, agglomerated IONs at both $0.1 \mathrm{mg} / \mathrm{ml}$ and $1 \mathrm{mg} / \mathrm{ml}$ 
also induced a slight decrease in the X2 population ( $\mathrm{p} \leq 0.05$ compared to solvent alone), together with a significant increase of the Xin gate $(\mathrm{p} \leq 0.05)$ (Fig. S6 $\left.{ }^{1}\right)$.

This data suggested that the mild effect of IONs on the balance among the different cell populations might owe to the physiological response of the planarian body towards external particles, regardless of their size.

\section{Conclusions}

Invertebrate species can be successfully used as alternatives to vertebrates in toxicology studies. Using invertebrate species for ecotoxicology studies reduces the costs of animal breeding, the difficulties of experimental manipulation and the ethical concerns, but yields useful toxicological information, from individual to population levels. Planarians have been used to assess the toxicity of chemicals (Best and Morita, 1991; Zhang et al., 2013; Hagstrom et al., 2015; Lowe et al., 2015), organophosphate pesticides (Hagstrom et al., 2015; Villar et al., 1993), or environmental pollutants in urban streams (Prá et al., 2005). Also, substances of unknown toxic potential, such as the alkaloid berberine (Balestrini et al., 2014), and nanoparticles (Kustov et al., 2014; Salvetti et al., 2015) have been tested in the planarian model.

There is still an ongoing debate about ION toxicity (Park et al., 2010; Srinivas et al., 2012; Szalay et al., 2012), especially considering the high local concentrations of IONs found nearby iron mines. This poses a serious threat to freshwater environments, especially where the environmental levels of IONs are not yet determined.

Our work shows that exposure of planarians to IONs, either as a waterborne or diet-borne pollutant, neither induced death, nor affected cell viability and oxidative stress (Fig. 2). Animals exposed to IONs displayed a slight change in the balance between the stem/progeny cells (X2) and the differentiated cells (Xin), as observed from flow cytometry data (Fig. 3). Gene expression data supported this observation, showing a reduction of the pan-neoblast marker smedwil and a corresponding increase of the post-mitotic marker NB32 $\mathrm{g}$ (Fig. 4). The mild changes at the cellular and molecular levels that were observed (Fig. 3-4) in response to IONs might possibly represent the physiological response to the physical presence of particles, similar to the molecular changes triggered by small injuries (e.g., incisions) in planarians (Owlarn et al., 2017). Further studies, however, are needed to clarify the actual mechanisms involved.

Recently, several reports assessed the toxicity of NPs, such as metal NPs, on aquatic animal models such as C. elegans, Daphnia sp., D. rerio, and others (Baumann et al., 2014; Lei et al., 2016; Magro et al., 2018; Remya et al., 2015; Taze et al., 2016). In those publications, the effects of the exposure to NPs were studied at the level of animal survival and behavior, cell viability, ROS production, and gene expression. However, none of these studies could consider the effects of NPs on stem cell dynamics, nor on regeneration processes, because none of the animal models used actually possesses pluripotent stem cells or regeneration capabilities. The planarian model, on the other hand, offers such a possibility, and recent studies in planarians anticipated the potential of this model organism in ecotoxicology studies aimed to assess the environmental safety of nanopollutants (Kustov et al., 2014; Salvetti et al., 2015). Our data suggests that IONs at concentrations relevant for environmental exposure (up to $1 \mathrm{mg} / \mathrm{ml}$ ) do not influence planarian regeneration, demonstrating the biocompatibility of IONs with planarians.

In conclusion, planarians represent a suitable aquatic model organism to study the environmental safety of nanopollutants that responds to the needs of experimental animal models in line with the $3 R$ strategy.

\section{References}

Andujar, P., Simon-Deckers, A., Galateau-Salle, F. et al. (2014). Role of metal oxide nanoparticles in histopathological changes observed in the lung of welders. Part Fibre Toxicol 11, 23. doi:10.1186/1743-8977-11-23

Andujar, P., Lacourt, A., Brochard, P. et al. (2016). Five years update on relationships between malignant pleural mesothelioma and exposure to asbestos and other elongated mineral particles. J Toxicol Environ Health B Crit Rev 19, 151-172. doi:10.1080/10937404.2016.1193361

Appiah-Adjei, E. K., Baidu, E. E., Adjei, K. A. et al. (2019). Potential heavy metal pollution of soils from artisanal automobile workshops: The case of Suame magazine, Ghana. Environ Earth Sci 78, 62. doi:10.1007/s12665-019-8069-7

Bahadar, H., Maqbool, F., Niaz, K. et al. (2016). Toxicity of nanoparticles and an overview of current experimental models. Iran Biomed J 20, 1-11.

Baker, R. T. M., Martin, P. and Davies, S. J. (1997). Ingestion of sub-lethal levels of iron sulphate by African catfish affects growth and tissue lipid peroxidation. Aquat Toxicol 40, 51-61. doi:10.1016/S0166-445X(97)00047-7

Balestrini, L., Isolani, M. E., Pietra, D. et al. (2014). Berberine exposure triggers developmental effects on planarian regeneration. Sci Rep 4, 4914. doi:10.1038/srep04914

Bastús, N. G., Casals, E., Ojea, I. et al. (2012). The reactivity of colloidal inorganic nanoparticles. In A. A. Hashim (ed.), The Delivery of Nanoparticles. Croatia: InTech. http://www. intechopen.com/books/the-delivery-of-nanoparticles/thereac tivity-of-colloidal-inorganic-nanoparticles

Baumann, J., Köser, J., Arndt, D. and Filser, J. (2014). The coating makes the difference: Acute effects of iron oxide nanoparticles on Daphnia magna. Sci Total Environ 484, 176-184. doi:10.1016/j.scitotenv.2014.03.023

Best, J. B. and Morita, M. (1991). Toxicology of planarians. Hydrobiologia 227, 375-383. doi:10.1007/BF00027626

Boiani, M., Gentile, L., Gambles, V. V. et al. (2005). Variable reprogramming of the pluripotent stem cell marker Oct4 in mouse clones: Distinct developmental potentials in different culture environments. Stem Cells 23, 1089-1104. doi:10.1634/ stemcells.2004-0352

Bundschuh, M., Filser, J., Lüderwald, S. et al. (2018). Nanop; 
articles in the environment: Where do we come from, where do we go to? Environ Sci Eur 30, 6. doi:10.1186/s12302-0180132-6

Cadmus, P., Brinkman, S. F. and May, M. K. (2018). Chronic toxicity of ferric iron for North American aquatic organisms: Derivation of a chronic water quality criterion using single species and mesocosm data. Arch Environ Contam Toxicol 74, 605-615. doi:10.1007/s00244-018-0505-2

Casals, E., Pfaller, T., Duschl, A. et al. (2010). Time evolution of the nanoparticle protein corona. ACS Nano 4, 3623-3632. doi:10.1021/nn901372t

Casals, E., Pfaller, T., Duschl, A. et al. (2011). Hardening of the nanoparticle-protein corona in metal (Au, $\mathrm{Ag}$ ) and oxide $\left(\mathrm{Fe}_{3} \mathrm{O}_{4}, \mathrm{CoO}\right.$, and $\left.\mathrm{CeO}_{2}\right)$ nanoparticles. Small 7, 3479-3486. doi:10.1002/smll.201101511

Casals, E. and Puntes, V. (2012). Inorganic nanoparticle biomolecular corona: Formation, evolution and biological impact. Nanomedicine (Lond) 7, 1917-1930. doi:10.2217/nnm.12.169

Casals, E., Gonzalez, E. and Puntes, V. (2012). Reactivity of inorganic nanoparticles in biological environments: Insights into nanotoxicity mechanisms. J Phys D Appl Phys 45, 443001. doi:10.1088/0022-3727/45/44/443001

Cebrià, F. and Newmark, P. (2005). Planarian homologs of netrin and netrin receptor are required for proper regeneration of the central nervous system and the maintenance of nervous system architecture. Development 132, 3691-3703. doi:10.1242/ dev.01941

Cebrià, F., Guo, T., Jopek, J. et al. (2007). Regeneration and maintenance of the planarian midline is regulated by a slit orthologue. Dev Biol 307, 394-406. doi:10.1016/j.ydbio. 2007.05.006

Chamorro, S., Gutierrez, L., Vaquero, M. P. et al. (2015). Safety assessment of chronic oral exposure to ironoxide nanoparticles. Nanotechnology 26, 205101. doi:10.1088/0957-4484/ 26/20/205101

Coricovac, D. E., Moaca, E. A., Pinzaru, I. et al. (2017). Biocompatible colloidal suspensions based on magnetic iron oxide. Nanoparticles: Synthesis, characterization and toxicological profile. Front Pharmacol 8, 154. doi:10.3389/ fphar.2017.00154

Dayem, A. A., Hossain, M. K., Lee, S. B. et al. (2017). The role of reactive oxygen species (ROS) in the biological activities of metallic nanoparticles. Int J Mol Sci 18, 120. doi:10.3390/ ijms 18010120

Ding, F., Radic, S., Chen, R. et al. (2013). Direct observation of a single nanoparticle-ubiquitin corona formation. Nanoscale 5 , 9162-9169. doi:10.1039/c3nr02147e

Duffin, R., Tran, L., Brown, D. et al. (2008). Proinflammogenic effects of low-toxicity and metal nanoparticles in vivo and in vitro: Highlighting the role of particle surface area and surface reactivity. Inhal Toxicol 19, 849-856. doi:10. 1080/08958370701479323

Dwivedi, S., Siddiqui, M. A., Farshori, N. N. et al. (2014). Synthesis, characterization and toxicological evaluation of iron oxide nanoparticles in human lung alveolar epithelial cells. Colloids
Surf B Biointerfaces 122, 209-215. doi:10.1016/j.colsurfb. 2014.06.064

Eisenhoffer, G. T., Kang, H. and Sánchez Alvarado, A. (2008). Molecular analysis of stem cells and their descendents during cell turnover and regeneration in the planarian Schmidtea mediterranea. Cell Stem Cell 3, 327-339. doi:10.1016/j.stem. 2008.07.002

Freyria, F. S., Bonelli, B., Tomatis, M. et al. (2012). Hematite nanoparticles larger than $90 \mathrm{~nm}$ show no sign of toxicity in terms of lactate dehydrogenase release, nitric oxide generation, apoptosis, and comet assay in murine alveolar macrophages and human lung epithelial cells. Chem Res Toxicol 25, 850-861. doi:10.1021/tx2004294

García, A., Espinosa, R., Delgado, L. et al. (2011). Acute toxicity of cerium oxide, titanium oxide, and iron oxide nanoparticles using standardized tests. Desalination 269, 136-141. doi:10.1016/j.desal.2010.10.052

Gentile, L., Cebria, F. and Bartscherer, K. (2011). The planarian flatworm: An in vivo model for stem cell biology and nervous system regeneration. Dis Model Mech 4, 12-19. doi:10.1242/ dmm.006692

Gottschalk, F., Sonderer, T., Scholz, R. W. and Nowack, B. (2009). Modeled environmental concentrations of engineered nanomaterials $\left(\mathrm{TiO}_{2}, \mathrm{ZnO}, \mathrm{Ag}, \mathrm{CNT}\right.$, fullerenes) for different regions. Environ Sci Technol 43, 9216-9222. doi:10.1021/ es9015553

Gualtieri, M., Skuland, T., Iversen, T. G. et al. (2012). Impor; tance of agglomeration state and exposure conditions for uptake and pro-inflammatory responses to amorphous silica nanoparticles in bronchial epithelial cells. Nanotoxicology 6, 700-712. doi:10.3109/17435390.2011.604441

Gupta, A. K. and Gupta, M. (2005). Synthesis and surface engineering of iron oxide nanoparticles for biomedical applications. Biomaterials 26,3995-4021. doi:10.1016/j.biomaterials. 2004.10.012

Hagstrom, D., Cochet-Escartin, O., Zhang, S. et al. (2015). Freshwater planarians as an alternative animal model for neurotoxicology. Toxicol Sci 147, 270-285. doi:10.1093/toxsci/ kfv129

Harcourt, G. A. (1942). Tables for the identification of ore-minerals by X-ray powder patterns. Amer Min 27, 63-113.

Hayashi, T., Asami, M., Higuchi, S. et al. (2006). Isolation of planarian X-ray-sensitive stem cells by fluorescence-activated cell sorting. Dev Growth Differ 48, 371-380. doi:10.1111/ j.1440-169X.2006.00876.x

Hayashi, T., Shibata, N., Okumura, R. et al. (2010). Single-cell gene profiling of planarian stem cells using fluorescent activated cell sorting and its "index sorting" function for stem cell research. Dev Growth Differ 52, 131-144. doi:10.1111/j.1440169X.2009.01157.x

Ishino, K., Kato, T., Kato, M. et al. (2015). Comprehensive DNA adduct analysis reveals pulmonary inflammatory response contributes to genotoxic action of magnetite nanoparticles. Int J Mol Sci 16, 3474-3492. doi:10.3390/ijms16023474

Kobayashi, N., Naya, M., Endoh, S. et al. (2009). Compara- 
tive pulmonary toxicity study of nano- $\mathrm{TiO}_{2}$ particles of different sizes and agglomerations in rats: Different short- and long-term post-instillation results. Toxicology 264, 110-118. doi:10.1016/j.tox.2009.08.002

Kodali, V., Littke, M. H., Tilton, S. C. et al. (2013). Dysregulation of macrophage activation profiles by engineered nanoparticles. ACS Nano 7, 6997-7010. doi:10.1021/nn402145t

Kornberg, T. G., Stueckle, T. A., Antonini, J. A. et al. (2017). Potential toxicity and underlying mechanisms associated with pulmonary exposure to iron oxide nanoparticles: Conflicting literature and unclear risk. Nanomaterials 7, 307. doi:10.3390/ nano7100307

Kustov, L., Tiras, K., Al-Abed, S. et al. (2014). Estimation of the toxicity of silver nanoparticles by using planarian flatworms. Altern Lab Anim 42, 51-58. doi:10.1177/026119291404200108

Lead, R. J., Batley, G. E., Alvarez, P. J. et al. (2018). Nanomaterials in the environment: Behavior, fate, bioavailability, and effects - An updated review. Environ Toxicol Chem 37, 20292063. doi:10.1002/etc. 4147

Lee, H. Y., Lee, S. H., Xu, C. et al. (2008). Synthesis and chaS racterization of PVP-coated large core iron oxide nanoparticles as an MRI contrast agent. Nanotechnology 19, 165101. doi:10.1088/0957-4484/19/16/165101

Lei, C., Zhang, L., Yang, K. et al. (2016). Toxicity of iron-based nanoparticles to green algae: Effects of particle size, crystal phase, oxidation state and environmental aging. Environ Pollut 218, 505-512. doi:10.1016/j.envpol.2016.07.030

Leung, A. M., Redlak, M. J. and Miller, T. A. (2008). Oxygen radical induced gastric mucosal cell death: Apoptosis or necrosis? Dig Dis Sci 53, 2429-2435. doi:10.1007/s10620-007-0165-y

Li, H., Zhou, Q., Wu, Y. et al. (2009). Effects of waterborne nano-iron on medaka (Oryzias latipes): Antioxidant enzymatic activity, lipid peroxidation and histopathology. Ecotoxicol Environ Saf 72, 684-692. doi:10.1016/j.ecoenv.2008.09.027

Liu, J. and Hurt, R. H. (2010). Ion release kinetics and particle persistence in aqueous nano-silver colloids. Environ Sci Technol 44, 2169. doi:10.1021/es9035557

Livak, J. K. and Schmittgen, T. D. (2001). Analysis of relative gene expression data using real-time quantitative PCR and the $2^{-\delta \delta C(T)}$ method. Method 25, 402-408. doi:10.1006/ meth.2001.1262

Lowe, J. R., Mahool, T. D. and Staehle, M. M. (2015). Ethanol exposure induces a delay in the reacquisition of function during head regeneration in Schmidtea mediterranea. Neurotoxicol Teratol 48, 28-32. doi:10.1016/j.ntt.2015.01.003

Lynch, I., Cedervall, T., Lundqvist, M. et al. (2007). The nanoparticle-protein complex as a biological entity; a complex fluids and surface science challenge for the $21^{\text {st }}$ century. Adv Colloid Interface Sci 167, 134-135. doi:10.1016/j.cis.2007.04.021

Magro, M., De Liguoro, M., Franzago, E. et al. (2018). The surface reactivity of iron oxide nanoparticles as potential hazard for aquatic environments: A study on Daphnia magna adults and embryos. Sci Rep 8, 13017. doi:10.1038/s41598-01831483-6

Massart, R. (1981). Preparation of aqueous magnetic liquids in alkaline and acidic media. IEEE Trans Magn 17, 1247-1248. doi:10.1109/TMAG.1981.1061188

Minard, K. R. and Wind, R. A. (2002). Picoliter ${ }^{1} \mathrm{H}$ NMR spectroscopy. J Magn Reson 154, 336-343. doi:10.1006/jmre. 2001.2494

Morgan, T. H. (1989). Experimental studies of the regeneration of Planaria maculata. Arch Entw Mech Org 7, 364-397, 34. doi:10.1007/BF02161491

Moritz, S., Stöckle, F., Ortmeier, C. et al. (2012). Heterogeneity of planarian stem cells in the $\mathrm{S} / \mathrm{G} 2 / \mathrm{M}$ phase. Int J Dev Biol 56, 117-125. doi:10.1387/ijdb.113440sm

Mouton, S., Willems, M., Houthoofd, W. et al. (2011). Lack of metabolic ageing in the long-lived flatworm Schmidtea polychroa. Exp Gerontol 46, 755-761. doi:10.1016/j.exger. 2011.04.003

Mudunkotuwa, I. A. and Grassian, V. H. (2011). The devil is in the details (or the surface): Impact of surface structure and surface energetics on understanding the behavior of nanomaterials in the environment. J Environ Monit 13, 1135. doi:10.1039/ c1em00002k

Namvar, F., Rahman, H. S., Mohamad, R. et al. (2014). Cytotoh xic effect of magnetic iron oxide nanoparticles synthesized via seaweed aqueous extract. Int J Nanomedicine 9, 2479-2488. doi:10.2147/IJN.S59661

Oberdörster, G., Maynard, A., Donaldson, K. et al. (2005). Principles for characterizing the potential human health effects from exposure to nanomaterials: Elements of a screening strategy. Part Fibre Toxicol 2, 8. doi:10.1186/1743-8977-2-8

Orii, H., Sakurai, T. and Watanabe, K. (2005). Distribution of the stem cells (neoblasts) in the planarian Dugesia japonica. Dev Genes Evol 215, 143-157. doi:10.1007/s00427-004-0460-y

Owlarn, S., Klenner, F., Schmidt, D. et al. (2017). Generic wound signals initiate regeneration in missing-tissue contexts. Nat Commun 8, 2282. doi:10.1038/s41467-017-02338-X

Park, E. J., Kim, H., Kim, Y. et al. (2010). Inflammatory responses may be induced by a single intratracheal instillation of iron nanoparticles in mice. Toxicol Sci 275, 65-71. doi:10.1016/j. tox.2010.06.002

Park, E. J., Oh, S. Y., Lee, S. J. et al. (2015). Chronic pulmonary accumulation of iron oxide nanoparticles induced th1type immune response stimulating the function of antigen-presenting cells. Environ Res 143, 138-147. doi:10.1016/j.envres. 2015.09.030

Pearson, B. J. and Sánchez Alvarado, A. (2010). A planarian p53 homolog regulates proliferation and self-renewal in adult stem cell lineages. Development 137, 213-221. doi:10.1242/ dev.044297

Pelclova, D., Zdimal, V., Kacer, P. et al. (2016). Oxidative stress markers are elevated in exhaled breath condensate of workers exposed to nanoparticles during iron oxide pigment production. $J$ Breath Res 10, 16004. doi:10.1088/17527155/10/1/016004

Peng, X. H., Qian, X., Mao, H. et al. (2008). Targeted magnetic iron oxide nanoparticles for tumor imaging and therapy. Int $J$ Nanomed 3, 311-321. 
Piccinno, F., Gottschalk, F., Seeger, S. et al. (2012). Industrial production quantities and uses of ten engineered nanomaterials in Europe and the world. J Nanopart Res 14, 1109. doi:10.1007/s11051-012-1109-9

Piella, J., Bastús, N. G. and Puntes, V. (2017). Modeling the optical responses of noble metal nanoparticles subjected to physicochemical transformations in physiological environments: Aggregation, dissolution and oxidation. Z Phys Chem 231, 3350. doi:10.1515/zpch-2016-0874

Podila, R., Chen, R., Ke, P. C. et al. (2012). Effects of surface functional groups on the formation of nanoparticle-protein corona. Appl Phys Lett 101, 263701. doi:10.1063/1.4772509

Prá, D., Lau, A. H., Knakievicz, T. et al. (2005). Environmental genotoxicity assessment of an urban stream using freshwater planarians. Mutat Res 585, 79-85. doi:10.1016/j. mrgentox.2005.04.002

Reddien, P. W. and Sánchez Alvarado, A. (2004). Fundamentals of planarian regeneration. Annu Rev Cell Dev Biol 20, 725757. doi:10.1146/annurev.cellbio.20.010403.095114

Reddien, P. W., Oviedo, N. J., Jennings, J. R. et al. (2005). SMEDWI-2 is a PIWI-like protein that regulates planarian stem cells. Science 310, 1327-1330. doi:10.1126/science. 1116110

Reidy, B., Haase, A., Luch, A. et al. (2013). Mechanisms of silver nanoparticle release, transformation and toxicity: A critical review of current knowledge and recommendations for future studies and applications. Materials 6, 2295. doi:10.3390/ ma6062295

Remya, A. S., Ramesh, M., Saravanan, M. et al. (2015). Iron oxide nanoparticles to an indian major carp, Lebeo rohita: Impacts on hematology, iono regulation and gill $\mathrm{Na}^{+} / \mathrm{K}^{+}$ATPase activity. J King Saud University - Sci 27, 151-160. doi:10.1016/j.jksus.2014.11.002

Rink, J. C. (2013). Stem cell systems and regeneration in planaria. Dev Genes Evol 223, 67-84. doi:10.1007/s00427-0120426-4

Russell, W. M. S. and Burch, R. L. (1959). The Principles of Humane Experimental Technique. London, UK: Methuen.

Sadeghi, L., Yousefi Babadi, V. and Espanani, H. R. (2015). Toxic effects of the $\mathrm{Fe}_{2} \mathrm{O}_{3}$ nanoparticles on the liver and lung tissue. Bratisl Lek Listy 116, 373-378. doi:10.4149/BLL_2015_071

Salvetti, A., Rossi, L., Lacopetti, P. et al. (2015). In vivo biocompatibility of boron nitride nanotubes: Effects on stem cell biology and tissue regeneration in planarians. Nanomedicine (Lond) 10, 1911-1922. doi:10.2217/nnm.15.46

Scimone, M. L., Kravarik, K. M., Lapan, S. W. and Reddien, P. W. (2014). Neoblast specialization in regeneration of the planarian Schmidtea mediterranea. Stem Cell Reports 3, 339-352. doi:10.1016/j.stemcr.2014.06.001

Semelka, R. C. and Helmberger, T. K. G. (2001). Contrast agents for MR imaging of the liver. Radiology 218, 27-38. doi:10.1148/radiology.218.1.r01ja2427

Shang, L., Nienhaus, K. and Nienhaus, G. U. (2014). Engineered nanoparticles interacting with cells: Size matters. J Nanobiotech 12, 5. doi:10.1186/1477-3155-12-5
Sharma, G., Kodali, V., Gaffrey, M. et al. (2014). Iron oxide nanoparticle agglomeration influences dose rates and modulates oxidative stress-mediated dose-response profiles in vitro. Nanotoxicology 6, 663-675. doi:10.3109/17435390.2013.822 115

Shen, J. M., Guan, X. M., Liu, X. Y. et al. (2012). Luminiscent/ magnetic hybrid nanoparticles with folate-conjugated peptide composites for tumor-targeted drug delivery. Bioconjug Chem 23, 1010-1021. doi:10.1021/bc300008k

Shvedova,A.A., Pietroiusti,A., Fadeel, B. and Kagan, V.E.(2012). Mechanisms of carbon nanotube-induced toxicity: Focus on oxidative stress. Toxicol Appl Pharmacol 261, 121-133. doi: 10.1016/j.taap.2012.03.023

Sighinolfi, G. L., Artoni, E., Gatti, A. M. and Corsi, L. (2016). Carcinogenic potential of metal nanoparticles in BALB/3T3 cell transformation assay. Environ Toxicol 31, 509-519.

Srinivas, A., Rao, P. J., Selvam, G. et al. (2012). Oxidative stress and inflammatory responses of rat following acute inhalation exposure to iron oxide nanoparticles. Hum Exp Toxicol 31, 1113-1131. doi:10.1177/0960327112446515

Stevens, A. S., Willems, M., Plusquin, M. et al. (2017). Stem cell proliferation patterns as an alternative for in vivo prediction and discrimination of carcinogenic compounds. Sci Rep 7, 45616. doi:10.1038/srep45616

Szalay, B., Tatrai, E., Nyiro, G. et al. (2012). Potential toxic effects of iron oxide nanoparticles in in vivo and in vitro experiments. J Appl Toxicol 32, 446-453. doi:10.1002/jat.1779

Taze, C., Panetas, I., Kalogianis, S. et al. (2016). Toxicity assessment and comparison between two types of iron oxide nanoparticles in Mytilus galloprovincialis. Aquat Toxicol 172, 9-20. doi:10.1016/j.aquatox.2015.12.013

Thomas, C. R., Ferris, D. P., Lee, J. H. et al. (2010). Noninvasive remote-controlled release of drug molecules in vitro using magnetic actuation of mechanized nanoparticles. $J$ Am Chem Soc 132, 10623-10625. doi:10.1021/ja1022267

Tolaymat, T., El Badawy, A., Genaidy, A. et al. (2017). Analysis of metallic and metal oxide nanomaterial environmental emissions. J Clean Prod 143, 401-412. doi:10.1016/j. jclepro.2016.12.094

Totsuka, Y., Ishino, K., Kato, T. et al. (2014). Magnetite nanoparticles induce genotoxicity in the lungs of mice via inflammatory response. Nanomaterials 4, 175-188. doi:10.3390/nano 4010175

Tran, T. and Gentile, L. (2018). A lineage cloud for neoblasts. Semin Cell Dev Biol 87, 22-29. doi:10.1016/j.semcdb. 2018.04.012

Van Roten, A., Zohir Abo-Zeid Barakat, A., Wouters, A. et al. (2018). A carcinogenic trigger to study the function of tumor suppressor genes in Schmidtea mediterranea. Dis Model Mech 11, dmm032573. doi:10.1242/dmm.032573

Veiseh, O., Gunn, J. W. and Zhang, M. (2010). Design and fabrication of magnetic nanoparticles for targeted drug delivery and imaging. Adv Drug Deliv Rev 62, 284-304. doi:10.1016/j. addr.2009.11.002

Villar, D., Li, M. H. and Schaeffer, D. J. (1993). Toxicity of or- 
ganophosphorus pesticides to dugesia dorotocephala. Bull. Environ. Contam Toxicol 51, 80-87. doi:10.1007/BF00201004

Vogg, M. C., Owlarn, S., Perez Rico, Y. A. et al. (2014). Stem cell-dependent formation of a functional anterior regeneration pole in planarians requires zic and forkhead transcription factors. Dev Biol 390, 136-148. doi:10.1016/j.yd $\theta$ bio.2014.03.016

Wagner, D. E., Wang, I. E. and Reddien, P. W. (2011). Clonogenic neoblasts are pluripotent adult stem cells that underlie planarian regeneration. Science 332, 811-816. doi:10.1126/science. 1203983

Wang, X., Ji, Z., Chang, C. H. et al. (2014). Use of coated silver nanoparticles to understand the relationship of particle dissolution and bioavailability to cell and lung toxicological potential. Small 10, 385. doi:10.1002/smll.201301597

Wang, Y., Deng, L., Caballero-Guzman, A. et al. (2016). Are engineered nano iron oxide particles safe? An environmental risk assessment by probabilistic exposure, effects and risk modeling. Nanotoxicology 10, 1545-1554. doi:10.1080/17435390. 2016.1242798

Watanabe, M., Yoneda, M., Morohashi, A. et al. (2013). Effects of $\mathrm{Fe}_{3} \mathrm{O}_{4}$ magnetic nanoparticles on A549 cells. Int $J$ Mol Sci 14, 15546-15560. doi:10.3390/ijms140815546

Weinstein, J. S., Varallyay, C. G. and E., D. (2009). Superparamagnetic iron oxide nanoparticles: Diagnostic magnetic resonance imaging and potential therapeutic applications in neurooncology and central nervous system inflammatory pathologies, a review. J Cereb Blood Flow Metab 30, 15-35. doi:10.1038/jcbfm.2009.192

Witchley, J. N., Mayer, M., Wagner, D. E. et al. (2013). Muscle cells provide instructions for planarian regeneration. Cell Rep 4, 633-641. doi:10.1016/j.celrep.2013.07.022
Wurtzel, O., Oderberg, I. M. and Reddien, P. W. (2017). Planarian epidermal stem cells respond to positional cues to promote cell-type diversity. Dev Cell 40, 491-504 e495. doi:10.1016/j. devcel.2017.02.008

Xing, M., Zhang, Y., Zou, H. et al. (2015). Exposure characteristics of ferric oxide nanoparticles released during activities for manufacturing ferric oxide nanomaterials. Inhal Toxicol 27, 138-148. doi:10.3109/08958378.2014.1001535

Zhang, J., Yuan, Z., Zheng, M. et al. (2013). Effects of n,n-dimethylformamide on behaviour and regeneration of planarian dugesia japonica. Toxicol Ind Health 29, 753-760. doi: $10.1177 / 0748233712443148$

Zhu, M.-T., Feng, W. Y., Wang, B. et al. (2008). Comparative study of pulmonary responses to nano- and submicron-sized ferric oxide in rats. Toxicology 247, 102-111. doi:10.1016/j. tox.2008.02.011

Zhu, M.-T., Feng, W.-Y., Wang, Y. et al. (2009). Particokinetics and extrapulmonary translocation of intratracheally instilled ferric oxide nanoparticles in rats and the potential health risk assessment. Toxicol Sci 107, 342-351. doi:10.1093/toxsci/kfn245

\section{Conflict of interest}

The authors declare no conflict of interest.

\section{Acknowledgements}

This work was supported by the European Commission under the Horizon 2020 program (grant agreement no 685817, HISENTS) and by the Fraunhofer Institute for Biomedical Engineering. TAT and BF were supported with PhD fellowships by Uni-Saar. The authors would like to thank Dr Julia Neubauer for revising the manuscript. 